\title{
Myeloperoxidase as an Effective Inhibitor of Hydroxyl Radical Production Implications for the Oxidative Reactions of Neutrophils
}

\author{
Christine C. Winterbourn \\ Pathology Department, Clinical School of Medicine, Christchurch Hospital, Christchurch, New Zealand
}

\begin{abstract}
Hydroxyl radicals have been generated from hydrogen peroxide and superoxide (produced with xanthine oxidase), and an iron (EDTA) catalyst, and detected with deoxyribose, or in some cases with benzoate or $\alpha$-keto- $\gamma$-methiolbutyric acid. Purified myeloperoxidase, and neutrophils stimulated with fMet-Leu-Phe and cytochalasin B, strongly inhibited this hydroxyl radical production in a concentration-dependent manner. Supernatants from stimulated cells also inhibited, and inhibition by cells or supernatant was prevented by azide. There was much less inhibition by myeloperoxidase-deficient neutrophils. Inhibition thus was due to myeloperoxidase released by the cells. With neutrophils stimulated with phorbol myristate acetate, which release very little myeloperoxidase, hydroxyl radical production was enhanced due to the additional superoxide produced by the cells. It is concluded that under conditions where neutrophils release myeloperoxidase as well as superoxide and hydrogen peroxide, breakdown of hydrogen peroxide by myeloperoxidase would make conditions unfavorable for hydroxyl radical production.
\end{abstract}

\section{Introduction}

Hydroxyl radicals are frequently considered as part of the microbicidal armory of polymorphonuclear leukocytes (neutrophils) (1-3). In response to inflammatory stimuli, neutrophils undergo an oxidative burst to produce superoxide and indirectly hydrogen peroxide (4). In principle, if a suitable transition metal ion complex were present, either intrinsically or in the surroundings of the cells, it could catalyze the conversion of these two species to the hydroxyl radical (5). This reaction is commonly referred to as the Haber-Weiss reaction, and occurs via the following mechanism $(6,7)$.

$$
\begin{aligned}
\mathrm{O}_{2}^{-}+\mathrm{Fe}^{3+}(\text { complex }) & \rightarrow \mathrm{O}_{2}+\mathrm{Fe}^{2+}(\text { complex }) \\
\mathrm{H}_{2} \mathrm{O}_{2}+\mathrm{Fe}^{2+}(\text { complex }) & \rightarrow \mathrm{OH}^{\bullet}+\mathrm{OH}^{-}+\mathrm{Fe}^{3+}(\text { complex })
\end{aligned}
$$

Other reducing agents, e.g., ascorbic acid, can also reduce ferric complexes and thus substitute for superoxide in reaction 1 (8). Whether neutrophils do in fact produce hydroxyl radicals is equivocal. Several groups have reported that the cells can produce a stronger oxidant than superoxide or hydrogen peroxide (9$15)$, but whether it is hydroxyl radical, or the conditions under which it is produced, has not been established. Further, all the biologically relevant iron chelates so far examined have low efficiencies as Haber-Weiss catalysts $(6,16)$.

Received for publication 25 October 1985 and in revised form 24 April 1986.

J. Clin. Invest.

(C) The American Society for Clinical Investigation, Inc.

0021-9738/86/08/0545/06 \$1.00

Volume 78, August 1986, 545-550
Even assuming a suitable catalyst were available, occurrence of the Haber-Weiss reaction requires reaction 2 to compete favorably with other reactions of $\mathrm{H}_{2} \mathrm{O}_{2}$. Most stimuli that induce superoxide production by neutrophils also cause the release of the azurophil granule protein, myeloperoxidase (17), and it is possible that reaction of the myeloperoxidase with hydrogen peroxide could inhibit hydroxyl radical production. Myeloperoxidase is usually considered as a catalyst of hypochlorous acid formation $(2,3)$, and therefore as a source of another potentially toxic neutrophil metabolite, but it could also be considered as a catalyst of peroxide removal. Its kinetic properties are such that it breaks down hydrogen peroxide regardless of hypochlorous acid formation, functioning as a catalase or peroxidase depending on the conditions under which it operates (18).

This study examines how myeloperoxidase affects production of hydroxyl radicals from superoxide and hydrogen peroxide. Hypoxanthine and xanthine oxidase in aerated buffer have been used as a source of superoxide and hydrogen peroxide, with $\mathrm{Fe}($ EDTA) present to give hydroxyl radicals in good yield via reactions 1 and 2 (16). Hydroxyl radicals have been detected primarily by measuring deoxyribose oxidation to thiobarbituric acid (TBA) ${ }^{1}$-reactive products (19), a reaction that does not occur with myeloperoxidase-derived oxidants. Hydroxyl radicals have also been detected by measuring hydroxylation products of benzoate (7) and ethylene production from $\alpha$-keto- $\gamma$-methiolbutyric acid $(\mathrm{KMB})(20,21)$. Although none of these reactions appears to be entirely specific $(16,22)$, when the reactants are $\mathrm{H}_{2} \mathrm{O}_{2}$, superoxide and $\mathrm{Fe}(\mathrm{EDTA})$, the evidence is strongly in support of the hydroxyl radical being the reactive species $(7,16)$. The effects of purified myeloperoxidase, and of neutrophils stimulated to release either very little or most of their granule contents, on the yield of hydroxyl radicals have been examined.

\section{Methods}

Neutrophils were isolated from the blood of healthy human donors by Ficoll-Hypaque centrifugation and dextran sedimentation of red cells (23). Residual red cells were removed by hypotonic lysis. Neutrophils from the myeloperoxidase-deficient donor contained $10 \%$ normal myeloperoxidase activity, measured in the cell sonicate.

Myeloperoxidase was purified from human neutrophil granules (24). The $\mathrm{A}_{430} / \mathrm{A}_{280}$ ratio was 0.73 and its concentration was calculated using $\epsilon_{430}=91,000 \mathrm{M}^{-1} \mathrm{~cm}^{-1}$ (with respect to iron). Myeloperoxidase activity released from neutrophils was measured with $o$-tolidine (25), and the method calibrated with purified enzyme. Xanthine oxidase (Sigma grade III, Sigma, St. Louis, MO) was separated from contaminant iron by diluting 1:5 in $25 \mathrm{mM}$ phosphate buffer, $\mathrm{pH} 7.4$, containing $4 \mathrm{mM}$ EDTA, then passing $0.1 \mathrm{ml}$ through a $2-\mathrm{ml}$ column of Sephadex G25 and collecting the protein fraction. Other biochemicals were from Sigma.

Reactions were all carried out in $10 \mathrm{mM}$ phosphate buffer, $\mathrm{pH} 7.4$, containing $\mathrm{NaCl}(0.138 \mathrm{M}), \mathrm{KCl}(10 \mathrm{mM}), \mathrm{CaCl}_{2}(0.2 \mathrm{mM}), \mathrm{MgCl}_{2}(0.2$

1. Abbreviations used in this paper: $\mathrm{KMB}, \alpha$-keto- $\gamma$-methiolbutyric acid; PMA, phorbol myristate acetate; TBA, thiobarbituric acid. 
$\mathrm{mM}$ ), and glucose $(0.5 \mathrm{mM})$ (incubation buffer). Glassware and plasticware were washed in $30 \%$ nitric acid to minimize iron contamination and solutions were prepared with deionized distilled water (Milli-Q System, Millipore Corp., Bedford, MA).

Superoxide and hydrogen peroxide were generated in air-exposed incubation buffer containing $0.15 \mathrm{mM}$ hypoxanthine, and $0.005-0.01$ $\mathrm{U}$ xanthine oxidase $/ \mathrm{ml}$. The standard hydroxyl radical generating system consisted of these reagents plus $2 \mu \mathrm{M} \mathrm{FeSO}{ }_{4}$ and $100 \mu \mathrm{M}$ EDTA. Rates of superoxide production were determined by measuring reduction of cytochrome $c\left(\Delta \epsilon_{550}\right.$ reduced - oxidized $\left.=2.11 \times 10^{4} \mathrm{M}^{-1} \mathrm{~cm}^{-1}\right)$ in the presence of catalase $(600 \mathrm{U} / \mathrm{ml})$. Either initial rates were measured by continuously monitoring $\mathrm{A}_{550}$ of $30 \mu \mathrm{M}$ cytochrome $c$, or the total amount of superoxide produced during the course of reaction was determined from the overall $\Delta \mathrm{A}_{550}$, measured with $100-200 \mu \mathrm{M}$ cytochrome $c$ present.

To generate hydroxyl radicals by $\gamma$-irradiation, solutions containing $10 \mathrm{mM}$ phosphate buffer and $10 \mathrm{mM}$ deoxyribose were bubbled with $\mathrm{N}_{2} \mathrm{O}$, transferred anaerobically to glass syringes, and irradiated for $2 \mathrm{~min}$ in a ${ }^{60} \mathrm{Co}$ source at a dose rate of $\sim 4.3 \mathrm{krad} / \mathrm{min}$. 1-ml portions were analyzed for TBA-reactive products as described. These experiments were kindly performed by Dr. H. C. Sutton.

Hydroxyl radical production was measured as oxidation of deoxyribose $(10 \mathrm{mM})(19)$. After reaction with the xanthine oxidase system, solutions $(1 \mathrm{ml})$ were mixed with $1 \mathrm{ml}$ trichloroacetic acid $(60 \mathrm{~g} / \mathrm{liter})$ and $0.5 \mathrm{ml} \mathrm{TBA}$ reagent $(1 \mathrm{~g} \mathrm{TBA}$ in $100 \mathrm{ml} 0.05 \mathrm{~N} \mathrm{NaOH})$, heated at $100^{\circ} \mathrm{C}$ for $10 \mathrm{~min}$, and their absorbance at $532 \mathrm{~nm}$ was measured. When neutrophils were present, the solutions were centrifuged for $10 \mathrm{~min}$ at 2,000 $\mathrm{g}$ before the heating step. Hydroxyl radicals were also detected either by gas chromatographic measurement of ethylene production from $\mathrm{KMB}(5 \mathrm{mM})(20,26)$ or fluorimetric measurement (at pH 12) (excitation $300 \mathrm{~nm}$, emission $410 \mathrm{~nm}$ ) of hydroxylation products from benzoate $(10 \mathrm{mM})(7)$. With both methods, the reaction with the xanthine oxidase system (in $1 \mathrm{ml}$ total volume) was terminated after $30 \mathrm{~min}$ by adding $50 \mu \mathrm{g}$ catalase. $\mathrm{NaOH}(50 \mu \mathrm{l}$ of $1 \mathrm{M})$ was added to the benzoate solutions before measuring fluorescence.

To detect hypochlorous acid, reactions with xanthine oxidase were carried out under the same conditions as for hydroxyl radical production except that $100 \mu \mathrm{M}$ monochlorodimedon replaced the deoxyribose and $\mathrm{A}_{290}$ was continuously monitored (18). In the absence of myeloperoxidase, $A_{290}$ increases linearly due to urate formation (18). This was used as a baseline for calculating absorbance changes due to myeloperoxidase-catalyzed chlorination of monochlorodimedon. Rates of urate and hypochlorous acid formation were calculated using $\epsilon_{290}$ values of 14,000 and $19,900 \mathrm{M}^{-1}$ liter $^{-1}$ for urate and monochlorodimedon, respectively.

Neutrophils were stimulated with either phorbol myristate acetate (PMA) or AMet-Leu-Phe and cytochalasin B. Since the dimethylsulfoxide (DMSO) and ethanol in which these were dissolved are both good hydroxyl radical scavengers, the volumes added were kept to a minimum. PMA stimulation: neutrophils $\left(2 \times 10^{7} / \mathrm{ml}\right.$ in incubation buffer at $\left.37^{\circ} \mathrm{C}\right)$ were stimulated with PMA $(0.5 \mu \mathrm{l}$ of $2 \mathrm{mg} / \mathrm{ml}$ in DMSO per ml cell suspension). fMet-Leu-Phe stimulation: to $2 \mathrm{ml}$ of neutrophil suspension $\left(2 \times 10^{7} / \mathrm{ml}\right)$ was added cytochalasin B $(0.25 \mu \mathrm{l}$ of $10 \mathrm{mg} / \mathrm{ml}$ in DMSO) followed by fMet-Leu-Phe ( $0.5 \mu \mathrm{l}$ of $1 \mathrm{mM}$ in $50 \%$ ethanol/water). Immediately after addition of either stimulant requisite volumes of the cell suspension were added to cytochrome $c$ to determine rates of superoxide production (as above) or were added to the hydroxyl radical generating system.

Hydroxyl radical scavenging by each solvent was determined by measuring concentration-dependent inhibition of deoxyribose oxidation caused by the solvent alone (Fig. 1). The maximum amount of DMSO used $(0.05 \mu \mathrm{l} / \mathrm{ml})$ was with $2 \times 10^{6}$ PMA-stimulated neutrophils, and this gave $25 \%$ inhibition. Solvent inhibition with $2 \times 10^{6} \mathrm{~m}$ Met-Leu-Phestimulated cells $(0.025 \mu \mathrm{l}$ DMSO and $0.05 \mu \mathrm{l}$ ethanol) was $13 \%$. Azide, which was used to inhibit myeloperoxidase, also gave concentrationdependent inhibition of deoxyribose oxidation by the xanthine oxidase system, presumably by scavenging hydroxyl radicals. Inhibition by the 0.5 -mM azide used was $30 \pm 4 \%$ (mean $\pm \mathrm{SD}$ from four sets of duplicate

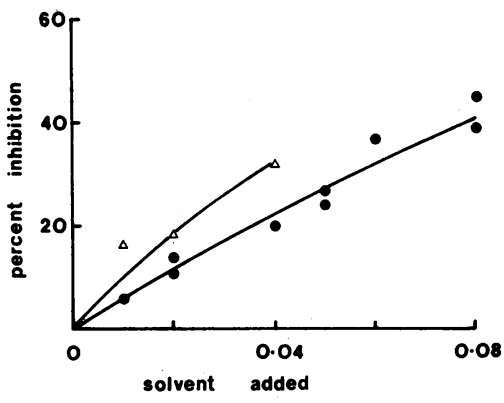

Figure 1. Effect of DMSO in microliters $(\bullet)$ and ethanol in microliters $\times 0.1(\Delta)$ on deoxyribose oxidation by hydroxyl radicals produced from xanthine oxidase. Reactions were carried out in air-exposed incubation buffer containing deoxyribose $(10 \mathrm{mM})$, hypoxanthine $(0.15$ $\mathrm{mM}), \mathrm{FeSO}_{4}(2 \mu \mathrm{M})$, EDTA $(100 \mu \mathrm{M})$ and xanthine oxidase $(\sim 0.01$ $\mathrm{U} / \mathrm{ml}$ giving a rate of superoxide production of $4 \mu \mathrm{M} / \mathrm{min}$ ). After 40 $\min$ at $37^{\circ} \mathrm{C}$, solutions were analyzed for TBA-reactive products.

assays). Superoxide production, measured as cytochrome $c$ reduction, was unaffected by azide.

\section{Results}

Effect of purified myeloperoxidase on hydroxyl radical production by the xanthine oxidase system. The standard system consisting of hypoxanthine, xanthine oxidase, and $2 \mu \mathrm{M}$ Fe(EDTA) in aerated buffer produced hydroxyl radicals and caused deoxyribose oxidation that was appropriately inhibited by superoxide dismutase, catalase, and the scavengers benzoate, formate, DMSO, and mannitol, as previously described (16). As shown in Fig. 2, deoxyribose oxidation was progressively inhibited by increasing concentrations of myeloperoxidase, with $5 \mathrm{nM}$ enzyme giving almost complete inhibition. In the presence of $0.5 \mathrm{mM}$ azide, the $A_{532}$ values in the presence and absence of $400 \mathrm{nM}$ myeloperoxidase were 0.216 and 0.210 , respectively, i.e., azide prevented inhibition by myeloperoxidase. The action of myeloper-

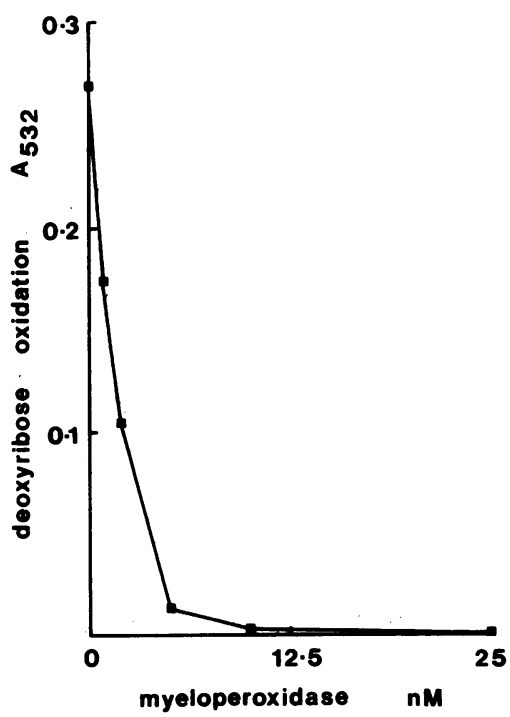

Figure 2. Effect of myeloperoxidase on deoxyribose oxidation by hydroxyl radicals produced from xanthine oxidase. Conditions are as in Fig. 1. 
oxidase was not as a hydroxyl radical scavenger, since addition of $25 \mathrm{nM}$ myeloperoxidase did not affect the yield of deoxyribose oxidation products from radiolytically generated hydroxyl radicals. $\mathrm{A}_{532}$ values were $0.321 \pm 0.004$ in the absence and $0.341 \pm 0.006$ in the presence of myeloperoxidase (means \pm SD for four determinations). Control experiments showed that the reaction of myeloperoxidase with hydrogen peroxide and chloride gave no deoxyribose oxidation, $100 \mathrm{nM}$ enzyme and one or four additions of $100 \mu \mathrm{M}$ hydrogen peroxide giving an increase in $\mathrm{A}_{532}$ of no more than $\mathbf{0 . 0 1 3}$.

Inhibition by a given concentration of myeloperoxidase depended on the xanthine oxidase concentration, i.e., the rate of generation of superoxide and hydrogen peroxide. With $2 \mathrm{nM}$ myeloperoxidase, and other conditions as in Fig. 2, halving the xanthine oxidase concentration increased inhibition from 55 to $75 \%$. However, varying the Fe(EDTA) concentration from 0.5 to $5 \mu \mathrm{M}$ made little difference to the percentage inhibition by 2 nM myeloperoxidase.

Effect of neutrophils on hydroxyl radical production by the xanthine oxidase system. Resting neutrophils and cells stimulated with either PMA, or fMet-Leu-Phe and cytochalasin B, were examined. These two stimulants were chosen because PMA causes very little azurophilic degranulation and hence myeloperoxidase release, whereas fMet-Leu-Phe plus cytochalasin B causes release of most of the myeloperoxidase from the cells (17). This was confirmed by measuring myeloperoxidase release, $8 \mathrm{pmol}$ from $10^{6} \mathrm{fMet}-$ Leu-Phe-stimulated neutrophils ( $~ 50 \%$ of the total), compared with 0.1 pmol from $10^{6}$ cells stimulated with PMA. Superoxide production was higher with PMA-stimulated cells, typically $\sim 5 \mathrm{nmol} / \mathrm{min}$ per $10^{6}$ cells, continuing for at least $30 \mathrm{~min}$. With fMet-Leu-Phe, superoxide production essentially ceased within $15 \mathrm{~min}$ and the total production was typically $40 \mathrm{nmol} / 10^{6}$ cells.

Initial experiments showed that $10 \mathrm{mM}$ deoxyribose or 100 $\mu \mathrm{M}$ EDTA (with or without $2 \mu \mathrm{M} \mathrm{Fe}^{2+}$ ) did not affect the rate of superoxide production by neutrophils stimulated with either PMA or fMet-Leu-Phe and cytochalasin B. When neutrophils were stimulated in the presence of hypoxanthine and xanthine oxidase, superoxide production was additive. In a typical experiment in which xanthine oxidase produced $2.4 \mathrm{nmol}$ superoxide $/ \mathrm{min}$ and $10^{6} \mathrm{PMA}$-stimulated cells $3.6 \mathrm{nmol} / \mathrm{min}$, superoxide production by the combination was $5.8 \mathrm{nmol} / \mathrm{min}$, i.e., there was no effect of neutrophils on the xanthine oxidase system, and no effect of xanthine oxidase on superoxide generation by the cells.

As shown in Fig. 3, addition of resting neutrophils to the xanthine oxidase hydroxyl radical generating system caused slight inhibition of deoxyribose oxidation. PMA-stimulated cells gave a concentration-dependent increase, although as these cells produced up to five times the superoxide generated by the xanthine oxidase, deoxyribose oxidation relative to superoxide production decreased. Neutrophils stimulated with PMA gave very little deoxyribose oxidation in the absence of $\mathrm{Fe}$ (EDTA), suggesting that the additional deoxyribose oxidation was due to increased production of hydroxyl radicals from the iron catalyst and neutrophil-derived superoxide. Neutrophils stimulated with fMetLeu-Phe were strongly inhibitory (Fig. 3). This inhibition was almost completely abolished by azide. Resting cells also had no effect on deoxyribose oxidation in the presence of azide (data not shown) and azide resulted in some enhancement of deoxyribose oxidation with PMA (Fig. 3).

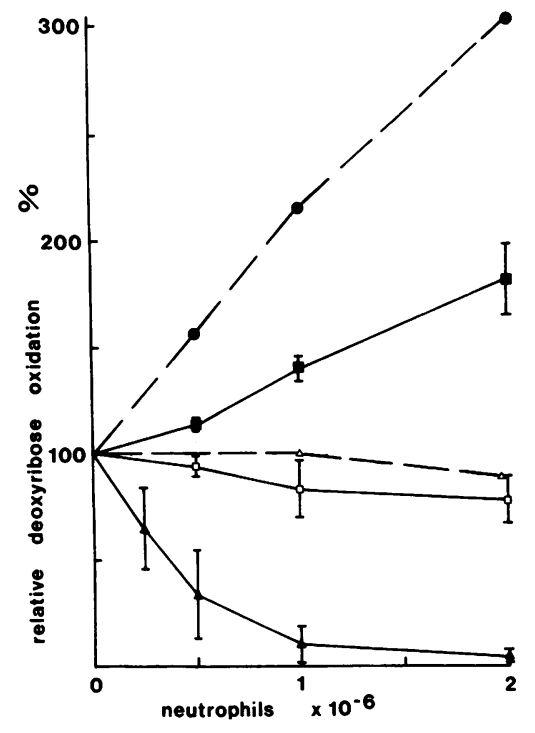

Figure 3. Effect of stimulated and unstimulated neutrophils on deoxyribose oxidation by hydroxyl radicals produced from xanthine oxidase. Reactions were carried out for $30 \mathrm{~min}$ at $37^{\circ} \mathrm{C}$ in air-exposed incubation buffer with reagents as in Fig. 1 (total vol $1 \mathrm{ml}$ ). Neutrophils were stimulated at $2 \times 10^{7} / \mathrm{ml}$ as described in Methods and the appropriate number immediately transferred to each reaction vessel. The amount of superoxide produced by the hypoxanthine and xanthine oxidase, or by the stimulated cells, was determined by simultaneous measurement of cytochrome $c$ reduction. Total amounts of superoxide produced during the reaction period were: xanthine oxidase $70 \mathrm{nmol} / \mathrm{ml}$; PMA $160 \mathrm{nmol} / \mathrm{ml}$ per $10^{6} \mathrm{cells}$; fMet-Leu-Phe and cytochalasin B 40 $\mathrm{nmol} / \mathrm{ml} / 10^{6}$ cells. Plotted values have been corrected for radical scavenging by DMSO and ethanol (see Methods). Values obtained in the presence of $0.5 \mathrm{mM}$ azide have also been corrected to allow for $28 \%$ inhibition of deoxyribose oxidation by azide at this concentration. Means \pm SD from five experiments are plotted, except the azide results, which are from one experiment. $\square$ resting cells; $\square$ PMA-stimulated cells; • PMA-stimulated cells plus azide; $\triangle$ fMet-Leu-Phe-stimulated cells; $\triangle \mathrm{fMet}$-Leu-Phe-stimulated cells plus azide.

Supernatants from fMet-Leu-Phe-stimulated neutrophils inhibited deoxyribose oxidation almost as effectively as did entire cell suspensions (Fig. 4). Hence, the inhibitory component was released from fMet-Leu-Phe stimulated cells. It is noteworthy that $0.5 \times 10^{6}$ neutrophils, which gave almost complete inhibition, released $\sim 4 \mathrm{nM}$ myeloperoxidase, which is very close to the concentration of purified enzyme required to prevent deoxyribose oxidation in Fig. 2. No inhibition was seen in the presence of azide, with the supernatant from $2 \times 10^{6}$ cells giving an $A_{532}$ value within $10 \%$ of the cell-free value. Inhibition was not due to hydroxyl radical scavenging, since deoxyribose oxidation by radiolytic hydroxyl radicals gave $A_{532}=0.277$ in the presence of supernatant from $1.5 \times 10^{6}$ neutrophils, compared with 0.293 in the presence of buffer containing equivalent volumes of the solvents used in cell stimulation. Supernatants from PMA-stimulated cells inhibited deoxyribose oxidation only very slightly (Fig. 4), which is consistent with the low level of myeloperoxidase release.

Myeloperoxidase-deficient neutrophils were compared with normal cells in their ability to inhibit deoxyribose oxidation by the xanthine oxidase system. As shown in Fig. 5, after stimulation with $\mathrm{fMet-Leu-Phe,} \mathrm{myeloperoxidase-deficient} \mathrm{cells} \mathrm{or} \mathrm{super-}$ natant gave much less inhibition than normal. 


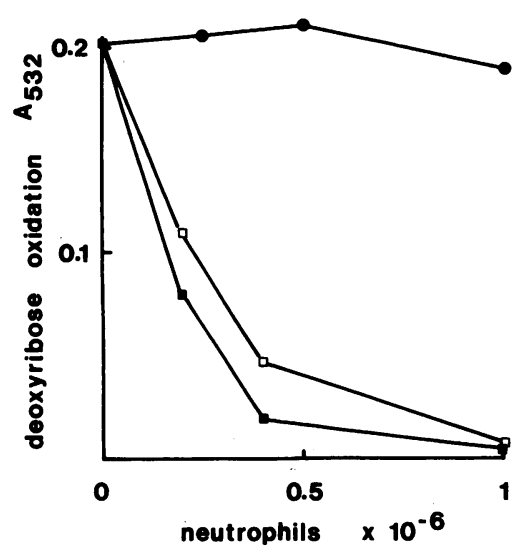

Figure 4. Comparison of supernatants from fMet-Leu-Phe-stimulated neutrophils with cell suspensions in their ability to inhibit hydroxyl radical production. Conditions were the same as for Fig. 3. - total cell suspension; $\square$ supernatant from the stated number of fMet-Leu-Phestimulated cells; $\bullet$ supernatant from PMA-stimulated cells. Both supernatants were separated by centrifugation $5 \mathrm{~min}$ after stimulation.

To ensure that inhibition by myeloperoxidase or stimulated neutrophils was not a specific feature of the deoxyribose assay, hydroxyl radicals produced by the xanthine oxidase-Fe(EDTA) system were also detected by measuring ethylene production from KMB and hydroxylation of benzoate. As shown in Table I, purified myeloperoxidase, and the supernatant from fMetLeu-Phe-stimulated neutrophils inhibited both ethylene production and benzoate hydroxylation. Myeloperoxidase and $\mathrm{H}_{2} \mathrm{O}_{2}$ and chloride, or the xanthine oxidase system in the absence of $\mathrm{Fe}$ (EDTA) gave no detectable benzoate hydroxylation, and $<2 \%$ of the ethylene production observed with the controls in Table I, i.e., neither method measured the $\mathrm{HOCl}$ produced under these conditions. The results with benzoate and KMB thus substantiate the findings with deoxyribose, that neutrophil myeloperoxidase inhibits the Fe(EDTA)-catalyzed production of hydroxyl radicals from hydrogen peroxide and superoxide.

Concomitant with inhibition of hydroxyl radical production

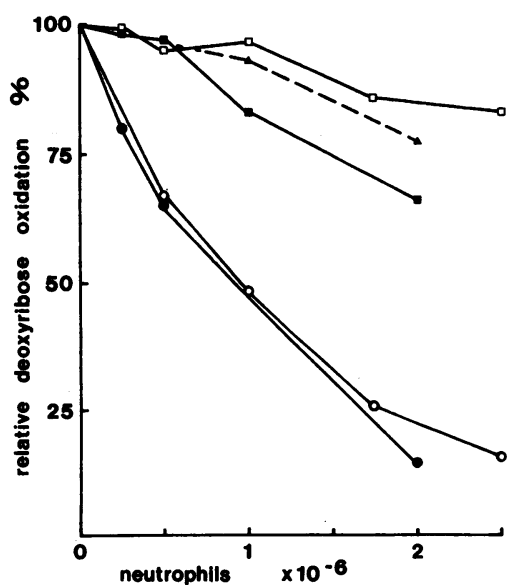

Figure 5. Comparison of normal and myeloperoxidase-deficient neutrophils in their ability to inhibit deoxyribose oxidation. Cells were stimulated with fMet-Leu-Phe and conditions are the same as for Fig. 4. Normal cells: $\bullet$ total cell suspension; $O$ cell supernatant. Myeloperoxidase-deficient cells; $\boldsymbol{\nabla}$ total cell suspension; $\square$ cell supernatant; $\Delta$ unstimulated cells.
Table I. Inhibition of Ethylene Production from $K M B$ and Benzoate Hydroxylation by Purified Myeloperoxidase and by Supernatants from fMet-Leu-Phe-stimulated Neutrophils

\begin{tabular}{lll}
\hline & Percent inhibition & \\
\cline { 2 - 3 } Inhibitor & $\begin{array}{l}\text { Ethylene } \\
\text { production }\end{array}$ & $\begin{array}{l}\text { Benzoate } \\
\text { hydroxylation }\end{array}$ \\
\hline Myeloperoxidase $(15 \mathrm{nM})$ & 70 & 97 \\
Supernatant from $10^{6}$ cells & 44 & 63 \\
\hline
\end{tabular}

Hydroxyl radicals were generated by the xanthine oxidase system as in Fig. 1, except solutions contained either $5 \mathrm{mM} \mathrm{KMB}$ or $10 \mathrm{mM}$ benzoate instead of deoxyribose. Results are expressed as relative gas chromatographic peak areas (ethylene production) or relative fluorescence (benzoate hydroxylation).

by supernatants from fMet-Leu-Phe-stimulated neutrophils, there was a parallel increase in hypochlorite formation (Table II). Comparable concentrations of supernatant from PMA-stimulated cells or myeloperoxidase-deficient cells stimulated with fMet-Leu-Phe, which scarcely inhibited hydroxyl radical production, also converted very little $\mathrm{H}_{2} \mathrm{O}_{2}$ to hypochlorous acid.

\section{Discussion}

Whether neutrophils can convert the superoxide and hydrogen peroxide that they produce to hydroxyl radicals is still an open question. Several reports of oxidation of methional, KMB, or DMSO by stimulated neutrophils (9-11), and some spin trapping studies (12-14) have implicated hydroxyl radicals. However, these observations must be interpreted cautiously since involvement of myeloperoxidase-derived oxidants has not been excluded (15), and no assessments were made of whether adventitious iron in the medium of the cells could have been responsible for catalyzing hydroxyl radical production. In recent experiments with iron contamination of the medium below $0.2 \mu \mathrm{M}$, no hydroxyl radical production by PMA-stimulated neutrophils could be detected as deoxyribose oxidation unless Fe(EDTA) was added (C. C. Winterbourn, unpublished observations). No endogenous catalyst of hydroxyl radical production by neutrophils has yet been identified. Lactoferrin appears to be a very poor catalyst of the Haber-Weiss reaction $(26,27)$, although there are reports to the contrary $(21,28)$. Further, the lactoferrin extracted from human neutrophil granules is $<25 \%$ iron saturated (M. C. M. Vissers and C. C. Winterbourn, unpublished observation), which suggests that it is not ideally suited for this role. Nevertheless, it is still possible that neutrophils could use an exogenous catalyst, present either in their surroundings or taken up during phagocytosis, as suggested by Repine et al. (29).

If it is assumed that neutrophils have access to a HaberWeiss catalyst, this reaction will occur only if it can outcompete alternative reactions of the hydrogen peroxide or superoxide produced by the cells. In the present study myeloperoxidase efficiently inhibited hydroxyl radical production from xanthine oxidase-generated superoxide and hydrogen peroxide and an Fe(EDTA) catalyst. This was not direct hydroxyl radical scavenging, and must have been due to removal of hydrogen peroxide, and possibly also superoxide (18). Addition of myeloperoxidase and chloride to hypoxanthine and xanthine oxidase results in production of hypochlorous acid (18). It thus appears 
Table II. Parallel Effects of Neutrophil Supernatants on Inhibition of Deoxyribose Oxidation and Formation of Hypochlorous Acid

\begin{tabular}{lllll}
\hline Neutrophils & Stimulant & Cells & $\begin{array}{l}\text { Inhibition of deoxyribose } \\
\text { oxidation }\end{array}$ & $\begin{array}{l}\text { Hypochlorous } \\
\text { acid formation }\end{array}$ \\
\hline & & Per $m l \times 10^{\circ}$ & $\%$ & $\%$ max \\
Normal & fMet-Leu-Phe & 1.25 & $50 \pm 2$ & 32 \\
Normal & fMet-Leu-Phe & 2.5 & $73 \pm 1$ & 60 \\
Myeloperoxidase deficient & PMA & 2.5 & $16 \pm 0$ & $15 \pm 2$ \\
& fMet-Leu-Phe & 2.5 & $4 \pm 3$ & $6 \pm 6$ \\
\hline
\end{tabular}

Cell supernatants were prepared and added to the xanthine oxidase hydroxyl radical generating system as described for Fig. 4. When measuring hypochlorous acid, deoxyribose was replaced by monochlorodimedon, and rates of chlorination determined by monitoring $\Delta \mathrm{A}_{290}$. The maximum rate was determined by adding excess purified myeloperoxidase, and corresponded to complete (106\%) conversion of $\mathrm{H}_{2} \mathrm{O}_{2}$ to hypochlorite. This was calculated knowing that $2 \mathrm{~mol} \mathrm{H}_{2} \mathrm{O}_{2}$ are formed for each mole of hypoxanthine oxidized to urate. Values for deoxyribose oxidation have been corrected for solvent inhibition.

that myeloperoxidase can divert the hydrogen peroxide from hydroxyl radical to hypochlorous acid production. The concurrent inhibition of deoxyribose oxidation and increase in hypochlorous acid formation seen on adding supernatant from stimulated neutrophils is a direct demonstration of this. At a molar concentration almost a thousand times lower than the Fe(EDTA) catalyst, myeloperoxidase was able to completely prevent hydroxyl radical formation.

Neutrophils added to the xanthine oxidase system also inhibited hydroxyl radical production. The greatest inhibition was seen with cells stimulated with fMet-Leu-Phe in the presence of cytochalasin B, which release most of their myeloperoxidase. The comparable inhibitory effects of cells and cell supernatant, and the prevention of inhibition by azide, strongly indicate that the effect is due to released myeloperoxidase. This interpretation is confirmed by the findings with myeloperoxidase-deficient neutrophils. Further, the degree of inhibition by fMet-Leu-Phestimulated cells was very close to that expected for the amount of myeloperoxidase released. PMA-stimulated cells that release very little myeloperoxidase but much more superoxide and hydrogen peroxide, gave more hydroxyl radical production than did the xanthine oxidase system alone. However, this was further increased by azide, implying a small inhibitory contribution by myeloperoxidase. The slight inhibition by resting neutrophils that was also prevented by azide could reflect peroxide breakdown either by intracellular myeloperoxidase or catalase, or by low levels of enzymes released from nonviable cells.

The implication from these results is that when neutrophils are stimulated to release myeloperoxidase as well as superoxide and hydrogen peroxide, breakdown of the hydrogen peroxide by the myeloperoxidase would make conditions unfavorable for hydroxyl radical production. It is very doubtful that appreciable hydroxyl radical production would take place unless a very efficient catalyst were present. Simple competition between myeloperoxidase and $\mathrm{Fe}$ (EDTA) was not found, which may not be surprising in view of the complex kinetics of the hydroxyl radicalproducing reaction. However, the low myeloperoxidase concentrations that were inhibitory suggest that a Haber-Weiss catalyst would need to be present at a considerably higher concentration than myeloperoxidase to be effective. This is probably unrealistic within the phagocytic vacuole. One must be cautious in extrapolating the present findings to likely events in the phagocytic vacuole, in view of the complex mechanism of myeloperoxidase action. Nevertheless, with myeloperoxidase (at 5\% of the total cell protein) being the most abundant protein released, it is unlikely that any other neutrophil constituent, even if capable of catalyzing hydroxyl radical production, would be released in sufficient amounts to do so at all efficiently.

Different stimuli induce different degrees of neutrophil degranulation (17). Particulate or surface stimuli generally release azurophil and specific granule contents, and would favor peroxide removal by myeloperoxidase. Soluble stimuli tend to be more selective. Notwithstanding the possibility that surface contact of the stimulated cells could enhance degranulation, it is possible that some soluble stimuli under physiological conditions could release superoxide and hydrogen peroxide and very little myeloperoxidase. Under these conditions, reaction of peroxide with a hydroxyl radical catalyst, if present, would be more likely. For the same reason, hydroxyl radical production could be more significant with myeloperoxidase-deficient cells.

The present findings lead to the conclusion that hydroxyl radicals may not be important for bacterial killing by neutrophils. These cells certainly have not optimized conditions for their formation. Other oxidative or nonoxidative microbicidal processes could be involved as alternative killing mechanisms (2, $3,30-32$ ), but as yet a critical role for any one has not been conclusively demonstrated. How myeloperoxidase contributes to the microbicidal activity of neutrophils is also not clear. It can convert hydrogen peroxide and chloride to hypochlorous acid $(2,3,33)$, and this reaction has been shown to occur in the environment of stimulated neutrophils $(18,34)$. It is efficient only at low $\mathrm{pH}$ and peroxide concentrations $(3,33,35)$, however, conditions that may not prevail in the phagosome (30). When hypochlorous acid is not formed, myeloperoxidase still decomposes hydrogen peroxide, but to oxygen and water, and thus functions as a catalase (18). When viewed in this light it is not surprising that it efficiently inhibits hydroxyl radical production.

\section{Acknowledgments}

I am grateful to Harry Sutton for carrying out the radiation experiments, to Terry Neal for neutrophil preparation, and to Margret Vissers for preparing the myeloperoxidase and for helpful discussion.

This work was supported by a grant from the Medical Research Council of New Zealand.

\section{References}

1. Badwey, J. A., and M. L. Karnovsky. 1980. Active oxygen species and the functions of phagocytic cells. Annu. Rev. Biochem 49:695-726. 
2. Babior, B. M. 1984. Oxidants from phagocytes. Agents of defense and destruction. Blood. 64:959-966.

3. Klebanoff, S. J. 1982. Oxygen dependent cytotoxic mechanisms of phagocytes. Adv. Host Def. Mech. 1:111-162.

4. Babior, B. M., R. S. Kipnes, and J. T. Curnutte. 1973. Biological defense mechanism. The production by leukocytes of superoxide, a potent bactericidal agent. J. Clin. Invest. 52:741-744.

5. Halliwell, B., and J. M. C. Gutteridge. 1984. Oxygen toxicity, oxygen radicals, transition metals and disease. Biochem. J. 219:1-14.

6. Sutton, H. C. 1985. Efficiency of chelated iron compounds as catalysts for the Haber-Weiss reaction. J. Free Radicals Biol. Med. 1:195-202.

7. Baker, M. S., and J. M. Gebicki. 1984. The effect of $\mathrm{pH}$ on the conversion of superoxide to hydroxyl free radicals. Arch. Biochem. Biophys. 234:258-264.

8. Winterbourn, C. C. 1979. Comparison of superoxide with other reducing agents in the biological production of hydroxyl radicals. Biochem. J. 182:625-628.

9. Tauber, A. I., and B. M. Babior. 1977. Evidence for hydroxyl radical production by human neutrophils. J. Clin. Invest. 60:374-379.

10. Weiss, S. J., R. K. Rustagi, and A. F. LoBuglio. 1978. Human granulocyte generation of hydroxyl radical. J. Exp. Med. 147:316-323.

11. Repine, J. E., J. W. Eaton, M. W. Anders, J. R. Hoidal, and R. B. Fox. 1979. Generation of hydroxyl radical by enzymes, chemicals and human phagocytes in vitro. J. Clin. Invest. 64:1642-1651.

12. Rosen, H., and S. J. Klebanoff. 1979. Hydroxyl radical generation by polymorphonuclear leukocytes measured by electron spin resonance spectroscopy. J. Clin. Invest. 64:1725-1729.

13. Green, M. R., H. A. O. Hill, M. J. Okolow-Zubkowska, and A. W. Segal. 1979. The production of hydroxyl and superoxide radicals by stimulated human neutrophils-measurements by EPR spectroscopy. Fed. Eur. Biochem. Soc. Lett. 100:23-26.

14. Bannister, J. V., P. Bellavite, A. Davoli, P. J. Thornalley, and F. Rossi. 1982. The generation of hydroxyl radicals following superoxide production by neutrophil NADPH oxidase. Fed. Eur. Biochem. Soc. Lett. 150:300-302.

15. Klebanoff, S. J., and H. Rosen. 1978. Ethylene formation by polymorphonuclear leukocytes. Role of myeloperoxidase. J. Exp. Med. 148:490-506.

16. Winterbourn, C. C., and H. C. Sutton. 1986. Iron and xanthine oxidase catalyse formation of an oxidant species distinguishable from $\mathrm{OH}^{\prime}$ : comparison with the Haber-Weiss reaction. Arch. Biochem. Biophys. 244:27-34.

17. Baggiolini, M., and B. Dewald. 1984. Exocytosis by neutrophils. In Current Topics in Immunobiology: Regulation of Leukocyte Function, R. Snyderman, editor. Chapter 8. Plenum Press, New York.

18. Winterbourn, C. C., R. Garcia, and A. W. Segal. 1985. Production of the superoxide adduct of myeloperoxidase (compound III) by stimulated neutrophils, and its reactivity with $\mathrm{H}_{2} \mathrm{O}_{2}$ and chloride. Biochem. J. 228:583-592.

19. Halliwell, B., and J. M. C. Gutteridge. 1981. Formation of a thiobarbituric acid-reactive substance from deoxyribose in the presence of iron salts-the role of superoxide and hydroxyl radicals. Fed. Eur. Biochem. Soc. Lett. 128:347-351.

20. Digiuseppi, J., and I. Fridovich. 1980. Ethylene from 2-keto-4thiomethyl butyric acid: The Haber-Weiss reaction. Arch. Biochem. Biophys. 205:323-329.

21. Ambruso, D. R., and R. B. Johnston, Jr. 1981. Lactoferrin enhances hydroxyl radical production by human neutrophils, neutrophil particulate fractions, and an enzymatic generating system. J. Clin. Invest. 67:352-360.

22. Bors, W., E. Lengfelder, M. Saran, C. Fuchs, and C. Michel. 1976. Reactions of oxygen radical species with methional: a pulse radiolysis study. Biochem. Biophys. Res. Commun. 70:81-87.

23. Böyum, A. 1968. Isolation of mononuclear cells and granulocytes from human blood. Isolation of mononuclear cells by one centrifugation; and of granulocytes by combining centrifugation and sedimentation at 1g. Scand. J. Clin. Lab. Invest. 21(Suppl. 97):77-89.

24. Matheson, N. R., P. S. Wong, and J. Travis. 1981. Isolation and properties of human neutrophil myeloperoxidase. Biochemistry. 20:325330.

25. Baggiolini, M., J. G. Hirsch, and C. de Duve. 1969. Resolution of granules from rabbit heterophil leukocytes into distinct populations by zonal sedimentation. J. Cell Biol. 40:529-541.

26. Winterbourn, C. C. 1983. Lactoferrin-catalysed hydroxyl radical production: additional requirement for a chelating agent. Biochem. $J$. 210:15-19.

27. Gutteridge, J. M. C., S. K. Paterson, A. W. Segal, and B. Halliwell. 1981. Inhibition of lipid peroxidation by the iron-binding protein lactoferrin. Biochem. J. 199:259-261.

28. Bannister, J. V., W. H. Bannister, H. A. O. Hill, and P. J. Thornalley. 1982. Enhanced production of hydroxyl radicals by the xanthinexanthine oxidase reaction in the presence of lactoferrin. Biochim. Biophys. Acta. 715:116-120.

29. Repine, J. E., R. B. Fox, and E. M. Berger. 1981. Hydrogen peroxide kills Staphylococcus aureus by reacting with staphylococcal iron to form hydroxyl radical. J. Biol. Chem. 256:7094-7096.

30. Segal, A. W. 1984. How do phagocytic cells kill bacteria? Med. Biol. 62:81-84.

31. Elsbach, P., and J. Weiss. 1981. Oxygen-independent bactericidal mechanisms of polymorphonuclear leukocytes. Adv. Inflam. Res. 2:95113.

32. Selsted, M. E., D. Szlarek, and R. I. Lehrer. 1984. Purification and antibacterial activity of antimicrobial peptides of rabbit granulocytes. Infect. Immun. 45:150-154.

33. Harrison, J. E., and J. Schultz. 1976. Studies on the chlorinating activity of myeloperoxidase. J. Biol. Chem. 251:1371-1374.

34. Weiss, S. J., R. Klein, A. Slivka, and M. Wei. 1982. Chlorination of taurine by human neutrophils. Evidence for hypochlorous acid generation. J. Clin. Invest. 70:598-607.

35. Andrews, P. C., and N. I. Krinsky. 1982. A kinetic analysis of the interaction of human myeloperoxidase with hydrogen peroxide, chloride ions, and protons. J. Biol. Chem. 257:13240-13245. 